\title{
Developing a Comprehensive Model of the Clothing Industry Using Fuzzy Goal Programming
}

\author{
Kamaleddin Rahmani ${ }^{1} \&$ Zarife Hemat-Ghadim ${ }^{2}$ \\ ${ }^{1}$ Department of Management, Tabriz Branch, Islamic Azad University, Tabriz, Iran \\ ${ }^{2}$ Department of Industrial Management, Tabriz Branch, Islamic Azad University, Tabriz, Iran \\ Correspondence: Zarife Hemat-Ghadim, Department of Industrial Management, Tabriz Branch, Islamic Azad \\ University, Tabriz, Iran. E-mail: zarife.hematghadim@gmail.com
}

Received: March 14, 2015

Accepted: March 16, 2015

Online Published: August 30, 2015

doi:10.5539/mas.v9n9p188

URL: http://dx.doi.org/10.5539/mas.v9n9p188

\begin{abstract}
The study aimed to develop a comprehensive model of the clothing industry using fuzzy goal programming. The research was descriptive and the study population consists of over 50 employees of statistical senior managers and directors of companies over 50 employees clothing industry. In this model firstly ideals and fuzzy goal programming are identified. After determining the goals of model the contribution of each goal is set. Finally the overall model has been developed. The model in a case study has been implemented in six periods for six product using data of Teb Posh Gostar Company. To collect data for determining goals of the model a questionnaire was used and was distributed among the statistical population after determining its validity and reliability. A paired questionnaire was used to determine the contribution of the indices of which represented the desired consistency rate of paired comparisons of utility. The results indicate that the developed model has a good reputation and can be used to produce a comprehensive program.
\end{abstract}

Keywords: production planning, clothing industry, fuzzy decision making, fuzzy goal programming

\section{Introduction}

The transition from the industrial age to the information age, the changes are significant at the international level. The speed of technological change, global competition and increasing customer expectations and preferences, punitive environments and critical business is a challenge for many companies (Arrenofsky, 2010, 71). Meanwhile, some companies are considering the high power of the technology, software and hardware, easily cope with these challenges and developments and give appropriate response, but some companies cannot cope with the changes. So, to save his life should make their own available resources (Aiyinggrong, 2007, 955). This requires a coherent and comprehensive program to help managers make the most out of limitations. One of the most important topics of interest to industry executives is production planning. Executives in various industries for production planning face with multiple objectives such as maximizing profits, minimizing cost and are sometimes in conflict with each other and achieving a goal is considered an obstacle to achieving other objectives. On the other hand, limited resources (capital, raw materials, manpower, location, etc.), created restrictions for organizations. Planning activities, in general, is to achieve long-term development goals through effective access to more specific short-term goals (Maroon, 2011). The managers have to use a method that, while respecting the constraints of existing organizational objectives make a reasonable estimate. Research techniques in operations with modeling issues, while considering limitations, optimize corporate purposes. All these techniques aim to increase productivity in the organization. The managers are always trying to identify and implement production system that systematically, increased costs and thereby prevent the creation of waste, increase competitiveness of companies (Callen et al, 2000,280). The clothing industry as an economic activity that uses more or less cheap labor is of the few industries that the developing countries have a comparative advantage in its production and exports. The industry in terms of both governments and employers countries mentioned is known as one of the main pillars of development which opens the door to foreign investment; generate foreign currency earnings, and is one way to achieve remarkably higher value-added industries and services. Investment opportunities in the industry is always the first step to enter the field of international trade and is evaluated as an opportunity for economic growth based on exports and many developed countries have tried all to use of their industrial capacity in this area (Maud, 2009, 272). The clothing industry is one of the 
largest businesses in the world that is accepted as an industry today, this work is dedicated to the special look that also meet the needs of all people, diversity, and creativity with art and technology with elegance; research and development has always had a special attraction and investment in the unit if combined with perseverance and Arts and Creativity thus quickly achieve results to create jobs and industrial progress and this job is not limited to any geographical boundaries as they are now in our country, the world's leading brands are welcomed (Mariano, 2011, 12 \& Johanson, 2009, 24). Accordingly, the production of clothing industry needs to give particular attention to plan their production. Especially the industry with numerous limitations to access to resources and these limitations should be able to control with proper planning. Ideal planning is one of the leading tools for planning in the field of versatile management decision analysis; the features of this tool is to achieve several objectives simultaneously on prioritization but the lack of goal programming problem is that all the parameters should be set carefully in deciding and all goals and constraints must be definitive (Kohansal \& Mohamadian, 2007). Clothing industry for many manufacturers in this sector is no exception to this, the purpose of this research is to develop a comprehensive model of the clothing industry using fuzzy goal programming. Kang (2012) in a study of production planning model as stated in the wood industry after presenting and reviewing the related literature this paper, presented a model in this paper. Maroon (2011) in a research on the combination of AHP and zero or ne ideal planning to select an advanced manufacturing system stated that the emerging technologies and their application in manufacturing organizations is vital to remain in the competition. Cheng and colleagues (2009) developed a linear programming model to deal with the uncertainty that exists in the limitations in the form of fuzzy. Transportation is also presented as an algorithm for solving linear programming model. This method greatly reduces the requirements made by the previous algorithm (Cheng, et al., 2009). Rong (2007) considered uncertainty based on fuzzy theory and limited the risk of failure based on a possible assessment. Alternatively, cost optimization problem as a linear programming problem with constraints waste fuzzy becomes a model (Aiying, 2007).

\section{Research Literature}

Production planning is one of the most important branches of industry-related applications which are obtained from the combination of the various techniques of industrial engineering with mathematical optimization techniques and heuristics. Large branches in engineering industries haven't high capacity of reception a variety of math and conceptual models. According to the definition, production planning means decisions about the resources that the organization needs for the future and allocation of these resources will be possible for the number of needed product and the lowest cost. In fact, production planning is meant to create a range for future production in organization

\subsection{Goal Planning}

In Multi Criteria Decision Making methods, we use several measures instead of using a measure of optimality. Multi-criteria decision making models can be divided into for multi-objective and multi-criteria decision-making models. In general, multi-objective models are used to design and multi-criteria models are used to select the top option. The main difference between the multi-objective decision making and multi-criteria models is that the former is defined on continuous decision space and the latter is defined on the discrete decisions space. Goal programming, first by Charnes and Cooper and Ferguson was introduced in 1955 (Charnes et al., 1995) but in 1961, the goal programming model is released by Charnes and Cooper (Charnes and Cooper, 1961). Methods of goal programming have common context. Their aim is to minimize the unfavorable deviations from purposes (Agawal \& Kholi, 1991). Goal programming is linear programming which can be used for multiple and conflicting goals. In this case, the model must be solved in such a way that each of the objectives to be achieved. Therefore, the sum of the deviations from the ideal should be minimized in objective function.

\subsection{Fuzzy Goal Programming}

Fuzzy set shows a group of members, in this set, there is no clear boundary between the members and non-members. $\mathrm{x}$ elements are members of $\mathrm{X}$ set. Therefore, fuzzy set $\mathrm{C}$ from $\mathrm{X}$ defines as set of couples.

$$
\mathrm{C}=\left[\mathrm{X}, \mu_{\mathrm{i}}(\mathrm{X})\right] \quad \mathrm{X} \in \mathrm{X}
$$

Where, the membership function is membership grade $\mathrm{X}$ in fuzzy set $\mathrm{C}$. Membership function is between [0-1], so that, 0 value shows lowest grade of membership and 1 value is the highest grade of membership.

\subsubsection{Memberships Function of Crisp Sets}

Membership function is defined as follows: 


$$
\mu_{\mathrm{A}}(\mathrm{x})= \begin{cases}1 & \mathrm{x} \in \mathrm{A} \\ 0 & \mathrm{x} \notin \mathrm{A}\end{cases}
$$

It can be expressed so that, if $\mathrm{x}$ is belonging to set $\mathrm{A}$, the membership function value is one, otherwise the value will be zero. It can be observed that, the domain of the membership function is reference set and its range is set of two members of $\{0,1\}$.

After Narsyman introduced fuzzy goal programming model, the studies were carried out on a fuzzy goal programming models to enhance computing performance. Hanan entered diversion goal programming variables into fuzzy goal programming model. To solve the model, just an ordinary linear programming formulation was necessary; Of course, this leads to an increase of the variables in formulating model (Chen and Tsai, 2001). Priority of objectives in the planning of an ideal planning is an important issue. For some causes are more important than others. Access to them is more important than others. Two different methods have been proposed for consideration of the importance.

\subsubsection{Sequential Method}

Decision-maker may consider priorities for goals, and objectives, assign different importance, which is known as sequential method. Solution is that objectives are divided into $\mathrm{K}$ priority. $\mathrm{K}$ is the number of fuzzy goals minus one. Then, k subsidiary issue is resolved. The achievement of the above objectives will be added to the least important issues as constraints (Chernes et al., 1995). The achievement of each of the sub-problems can be achieved. Although this method solves the model taking into account the importance of arbitrary decisions, efficiency is greatly reduced. In hierarchical structure which is provided by TIVARY, like other sequential methods, top objectives must be achieved. The higher objectives should be more important than the lower goals. Wang and $\mathrm{Fu}$ are used different membership functions to express the objectives priority which were obtained by using fuzzy set operations such as expansion and contraction. Chen and Tsai model suggests model that priorities objectives according to importance expressed by decision-maker. In this way, the decision maker determines the minimum values for each level of achievement. Objectives are modeled using appropriate access levels. Akoz and Petrovic, raised a fuzzy goal programming model where the importance level of aspiration, precisely defined and phase relationships are shown. This model proposed a new structure for objective function. The objective function is the sum of all achieving levels to goals and degree of satisfaction. In fact, the precise determination of the priority objectives in multi-objective problems is not easy. Uncertainty is unavoidable in expressing significance of goals. Or prioritization of objectives, from perspective of decision maker is ambiguous. The decisions and dependencies space between goals is another factor that influences on determination of objectives. Therefore, we need a fuzzy goal programming model to the uncertainty considered and provide a flexible tool for decision (Akos and Petrovic, 2007).

\section{Research Methodology}

This research is based on the objective is applied research and the nature of work is descriptive modeling. The statistical population includes all industrial workshops which is above 50 employees. According to the latest statistics from the Statistical Center of Iran, these workshops include 50 to 99 people, 12 workshops and 16 workshops for more than 100 people. Data have been collected from CEOs and directors of these workshops that a total of 56 persons are selected as the statistical population. Due to the limitation of the study population, no sampling has been done and the whole society will be examined and navigated. In this study Teb Posh Gostar Company was selected as a pilot location of research. In this study, in order to develop a model a fuzzy goal programming is applied.

\section{Analysis of Research Data}

\subsection{Goal Restrictions}

The objective function is defined as the ideal in the model. To determine the goals after studying and senior managers and production managers' opinions, and concluding comments 3 main goals was chosen as ideal as follows:

- Profit Goals

Thus we would like to minimize deviation from negative left inequality to the right.

$$
\left(X_{L t} \times b_{L t}\right)+S N_{L t}-S P_{L t}=G_{L t}
$$

- Demand Goals

Thus we would like to minimize deviation from negative left inequality to the right.

$$
X_{L t}-I K_{L t-1}+I K_{L t}+D N_{L t}-D P_{L t}=d_{L t}
$$


- $\quad$ Stock Goals

Thus we would like to minimize deviation from positive left inequality to the right.

$$
I K_{L t}+I N_{L t}-I P_{L t}=I_{L t}
$$

\subsection{System Limitations}

- Limited Production Capacity of each Workshop

Since each of the workshops is limited in production, so for each of the workshops system limitation can be written as:

$$
\sum_{L=1}^{m} X_{L t}=C_{i j}, \quad t=1,2,3, \ldots, n
$$

- Stock Limitation of the first inventory planning

With the assumptions of the model, given that the first planning period, the value of any goods as beginning inventory is planned, the limitations of the system are written as follows:

Based on the constraints written, the final state of the research will be as follows:

$$
\begin{aligned}
& \operatorname{MinZ} Z=w_{1} \sum_{L=1}^{m} \sum_{t=1}^{n} S N_{L t}+w_{2} \sum_{L=1}^{m} \sum_{t=1}^{n} D N_{L t}+w_{3} \sum_{L=1}^{m} \sum_{t=1}^{n} I P_{L t} \\
& S t: \\
& \left(X_{L t} \times b_{L t}\right)+S N_{L t}-S P_{L t}=G_{L t} \\
& X_{L t}-I K_{L t-1}+I K_{L t}+D N_{L t}-D P_{L t}=d_{L t} \\
& I K_{L t}+I N_{L t}-I P_{L t}=I_{L t} \\
& \sum_{L=1}^{m} X_{L t}=C_{i j}, \quad t=1,2,3, \ldots, n \\
& I K_{L t-1}=I_{L t-1}
\end{aligned}
$$

According the fuzzy approach used in this research. Based on symmetric fuzzy modeling approach fuzzy goal programming model is as follows.

$$
\begin{aligned}
& \operatorname{Max}=\lambda \\
& S t: \\
& w_{1} \sum_{L=1}^{m} \sum_{t=1}^{n} S N_{L t}+w_{2} \sum_{L=1}^{m} \sum_{t=1}^{n} D N_{L t}+w_{3} \sum_{L=1}^{m} \sum_{t=1}^{n} I P_{L t}-P_{i} Y_{i} \leq Z+P_{i t} \\
& \left(X_{L t} \times b_{L t}\right)+S N_{L t}-S P_{L t}=G_{L t} ; \\
& X_{L t}-I K_{L t-1}+I K_{L t}+D N_{L t}-D P_{L t}-P_{i t} \lambda \geq d_{L t}-P_{i t} ; \\
& X_{L t}-I K_{L t-1}+I K_{L t}+D N_{L t}-D P_{L t}+P_{i t} \lambda \leq d_{L t}+P_{i t} \\
& I K_{L t}+I N_{L t}-I P_{L t}=I_{L t} ; \\
& \sum_{L=1}^{m} X_{L t}=C_{i j}, \quad t=1,2,3, \ldots, n \\
& I K_{L t-1}=I_{L t-1}
\end{aligned}
$$

\section{Conclusion}

In this study, using the t-test the goals of the clothing industry has been determined the results are presented in Table.

Table 1. The identification results goals of clothing industry

\begin{tabular}{ccc}
\hline Result & $\mathrm{t}$ & Goal \\
\hline Confirm & 4.438 & Demand Goal \\
Reject & -7.797 & Cost Goal \\
Reject & 0.476 & Workshop Capacity Goal \\
Confirm & 2.957 & Profit Goal \\
Confirm & 2.211 & Stock Goal \\
\hline
\end{tabular}


According to the test conducted in this study, three goals of demand, profits and stocks were identified as research goals. Perhaps the main reason that cost goal is not chosen among the goals is because of the lack of clear information on the price and maybe managers believe the benefit goal was somehow derived from a company's costs, and if a company can achieve these goals, the company in fact has the means to properly cover costs. Then after identifying research goals, contribution of goals was determined using paired comparison questionnaire. Table 2 shows the contribution of each of the goals.

Table 2. The contribution of each goal

\begin{tabular}{cc}
\hline Goal Contribution & Goal \\
\hline 0.6758 & Demand Goal \\
0.2360 & Profit Goal \\
0.0882 & Stock Goal \\
\hline
\end{tabular}

Based on the weights obtained for each of the goals, demand goals with $0 / 6758$ contribution gain the first place, profit goal gain $0 / 2360$ gain second place and stock goals with 0/0882 gain third place. The researcher expects that among the selected goals, the benefit goal gains the contribution; however, the results showed that the contribution of demand goal is more than the profit contribution. The researcher also conducted an interview with some clothing industry managers came to the conclusion that the managers of this industry pay more attention to sell and give priority to adequate market in their business. This can largely be reasonable and sales as an indicator of a company's performance reflects its growth. After selecting and evaluating the contribution of each goal; the model was implemented using data of Teb Posh Gostar Company. To implement the model using the last six months sale, demand forecast for the next six months was performed. The model was scheduled based on six months assumption. The model has been formulated with 290 variables and 163 constraints. The model has been implemented using the data to determine the amount of deviation in the objective function. The fuzzy model was developed and implemented the results for each of products in the next six periods is as table (3), respectively.

Table 3. Results of the model for production planning in six periods

\begin{tabular}{ccccccc}
\hline Gynecology & Angiography & Brain & Bypass & Laparotomies & General & $\begin{array}{c}\text { Product } \\
\text { Period }\end{array}$ \\
\hline 20707 & 15665 & 5417 & 9487 & 6469 & 17265 & 1 \\
21590 & 15847 & 5587 & 9092 & 5112 & 17763 & 2 \\
22472 & 16093 & 5757 & 8689 & 3773 & 18261 & 3 \\
23355 & 16232 & 5929 & 8304 & 1081 & 18759 & 4 \\
24238 & 16424 & 6097 & 7909 & 1075 & 19257 & 5 \\
25121 & 16616 & 6267 & 7575 & 0 & 19775 & 6 \\
\hline
\end{tabular}

Despite the care taken in the model it can be seen in table (3) the value of some variables to zero and the value of some are poor. In the analysis of the situations obtained several points could be noted:

- The first possibility about the zero or poor digits is that given the coefficients of the model, the optimal zero will be achieved and, in fact, the answer zero or low is the optimal solution of the problem.

- The second possibility of the above numbers is error or failure of the model coefficients if better the figures could be given to the model as coefficients, the results will be better.

- A third possibility is that the contribution of goals according to industry managers it also can be another reason of the figures obtained. In other words, because the figures are obtained by the managers, it does not fit with reality and leads to undesirable and zero figures, if these coefficients can be corrected better conditions can be achieved.

\section{References}

Agawal, V., \& kholi, P. V. (1991). Computer aided robot selection, the multiple attribute making approach. 
International journal of production research, 29(8), 1629-1644.

Arronofsky, J. S., Dutton, J. M., \& Tayyabkhan, M. T. (2010). Managerial Programming with Linear Programming in process Industry Operations, New York, John Wiley and Sons Inc.

Callen, J., Fader, C., \& Kirnksky, I. (2000). Just-in-time: a cross-sectional plant analysis. International Journal of Production Economics, 63, 277-301.

Charnes, A., Cooper, W., \& Fergusen, R. (1995). Optimal estimation of executive compensation by linear programming. Management science, 1, 138-151.

Cheng, G. H., Fan, Y. R., Huang, G. H., Li, Y. P., \& Cao, M. F. (2009). A fuzzy linear programming approach for municipal solid waste management under uncertainty, Engineering optimization.

Kang, H. (2012). High-Performance Manufacturing Evidence From the Automotive Components Industry. Organization Studies, 18(5), 783-98.

Kohansal, M., \& Mohamadian, F (2007). Application of goal programming in determination of optimal pattern of corps cultivation, 6th conference of Agricultural Economy.

Mariano, J., Mar Arenas, Amelia, B., \& Rodriguez, M. V. (2005). Linear programming with fuzzy parameters: An interactive method resolution, European Journal of Operational Research, 61, 1-16.

Maroon, L. (2011). An Introduction to lean thinking, Lean Enterprise Research Centre, Cardiff Business School.

Maud Gothe-Lundgren, Jan, Lundgren, T., \& Jan A. (2009). An optimization model for refinery production scheduling. International Journal of Production Economics, 78, 225-270, 280.

Rong, A. (2007). Fuzzy chance constrained linear programming model for optimizing the scrap charge in steel production. Technical university of Denmark, 953-964.

\section{Copyrights}

Copyright for this article is retained by the author(s), with first publication rights granted to the journal.

This is an open-access article distributed under the terms and conditions of the Creative Commons Attribution license (http://creativecommons.org/licenses/by/3.0/). 